\title{
"No que toca à ama": A maternidade nas cartas entre D. Leonor de Portugal e o morgado de Mateus
}

\author{
"About the wet nurse": Maternity on the letters between \\ D. Leonor de Portugal and the morgado of Mateus
}

Elen Biguelini

Universidade de Coimbra

\section{DoI}

https://doi.org/10.37508/rcl.2021.n45a428

\begin{abstract}
RESUMO
Durante o século XVIII existiu uma mulher, D. Leonor de Portugal (1722c.1806), que cuidou da Casa de seu marido, morgado de Mateus (17221798), +a carreira política e estada deste no Brasil. Por meio das cartas entre o casal, evidencia-se um cotidiano familiar e, em especial, a afinidade entre figura materna com seus filhos. A maternidade é, então, o tema deste texto, que analisa nas missivas desta senhora a relação feminina entre maternidade e poder. A relação entre a esposa do morgado e suas amas-de-leite, assim como o sentimento maternal e o cuidado para com a saúde e a educação de seus filhos são os temas centrais da análise, que está baseada na crítica literária feminista e na história das mulheres, bem como em autoras e autores que trataram da história da maternidade e do amor materno.
\end{abstract}

Palavras-Chave: história das mulheres, século XVIII, Portugal, escrita epistolar, maternidade. 


\section{Abstract}

During the XVIII century there was a lady, D. Leonor de Portugal (1722c.1806), who ran her husband's -the morgado of Mateus, (1722-1798) - house and land during his political career and stay in Brazil. In the couple's letters, it is evident the family's day-to-day life, and, specially, the mother's relationship with her children. Maternity is, then, the central theme of this text, that analyses in her letter's female life, maternity, and power. The relationship between the morgado's wife and her wet nurses, as well as the maternal feelings and the care with her children's health and education is at the center of this analysis, based on the feminist literary criticism, women history and in authors who work with maternity history and maternal love.

KEYWORDS: women's history, XVIII century, Portugal, epistolary writing, maternity

\section{Introdução}

Durante o final do século XVIII, a correspondência entre uma esposa e seu marido demonstrou a forma como a sociedade portuguesa observava a maternidade, o sentimento materno e paterno, a questão das amas de leite e a dor perante o falecimento dos filhos. Por meio dos comunicados que podem ser encontrados em suas missivas e que atravessavam Portugal ou o oceano Atlântico, pode-se perceber a importância dos filhos no cotidiano da Casa portuguesa e a forma como a mulher comandava o lar na ausência do marido, demonstrando que também elas detinham poder, ao menos local.

A vida do casal sobre o qual nos debruçamos neste texto não está completamente representada por meio de suas correspondências, mas através delas se pode perceber a posição de importância primordial dada aos filhos e, em especial, a sua educação, por parte de membros da fidalguia portuguesa.

A maternidade era, neste período, uma necessidade na vida feminina. D. Leonor fora educada para a função de mãe. Mas, ao contrário do que era o comum ou esperado entre as senhoras portuguesas, ela 
vai além do simples comando da educação de seus filhos, tendo interesse também na gestão do lar como um todo, em especial naquilo se refere à vida física e intelectual de seus filhos. Além disto, ela não faz suas escolhas sozinhas, relegando ao marido algumas questões que eram, neste período, prioritariamente femininas; dando ao pai uma participação relevante quanto a sua relação com os filhos.

\section{Luis e D. Leonor}

D. Luís António de Sousa Botelho Mourão (1722-1798), o quarto morgado de Mateus, era filho de António José Alvares Mourão (1688-1743) e de D. Joana Maria de Sousa Mascarenhas e Queiros (1695-1723). Nasceu em 1722. Dois anos depois, após a morte de sua mãe, foi levado ao Castelo de Vila Viana, onde foi educado por seu avô materno, D. Luís António de Sousa (1671-1749). Permaneceu neste local até a morte de seu pai, em 1746, quando assumiu o morgadio e retornou à Mateus.

Sete anos após a volta para Mateus, D. Luís teve uma criança ilegítima com D. Luísa Vitória Tores de Aguião (?-?), filha do desembargador Manuel dos Reis Maciel de Aguião (?-?), morgado de Miranques em Monção. Esta criança, D. Teresa Luísa de Jesus de Sousa Maciel (1752-1802), passou a viver com ele e seus familiares em Mateus após o falecimento de sua mãe, quando D. Luís já estava casado. Além da jovem, também habitavam a casa de Mateus dois irmãos religiosos de seu pai; D. Isabel, filha de um de seus tios, e algumas filhas naturais de seu avô paterno, D. Maria e D. Maria Eufrásia. Percebe-se, então, que a família tinha como costume o contato com filhas ilegítimas, frutos de relações ilícitas de suas personagens masculinas (os 'chefes' da Casa).

D. Leonor Josefa Ana Luiza de Portugal (1722-c.1806), filha de Rodrigo de Sousa Coutinho Castelo-Branco e Menezes (?-1748) e Maria Antónia de São Boaventura Menezes Monteiro Paim (?-?), nasceu no mesmo ano em que seu futuro marido e era uma mulher educada e pertencente à Corte em Lisboa (devido à proximidade de seus fa- 
miliares à família real). Ao contrário da grande maioria de mulheres portuguesas, ela havia tido acesso a uma vasta formação: sabia francês, inglês, latim, matemática básica, além de bordado e costura (práticas socialmente consideradas como femininas). Sua mãe era viúva e recebia a aristocracia lisboeta em sua casa, e os Condes de Redondo eram seus parentes, sendo que frequentemente visitava sua Tia Redondo em Lisboa. Assim, frequentava a mais alta Corte lisboeta, e mantinha relações com grande parte desta. Seus dois irmãos, D. Francisco Inocêncio de Sousa Coutinho e D. Vicente de Sousa Coutinho tiveram marcantes carreiras diplomatas, demonstrando a posição social de relevo de sua família.

D. Luís e D. Leonor tiveram um casamento consideravelmente tardio para a elite portuguesa do século XVIII. Ponderando que neste período o casamento era uma aliança, esta "importa mais que o matrimónio" e "casa-se mais com uma família do que com uma pessoa" (BOLOGNE, 1995, p. 221). Desta forma, a união matrimonial é um "compromisso de associação permanente entre duas famílias" (CASEY, 1992, p. 111). Isto se reflete na união entre dona Leonor e seu marido. As conversas entre suas famílias iniciaram quando ambos tinham 31 anos, sendo que o casamento só veio acontecer três anos depois, em 1754. A partir de então, o casal passou a viver na cidade do Porto e, após o nascimento do primeiro filho, mudaram-se permanentemente para a casa em Mateus.

Os primeiros anos da vida em casal parecem ter sido felizes. Suas cartas demonstram que sentiam saudade e preocupação mútua. No entanto, o trabalho do morgado o retirava do lar por diversas vezes ${ }^{1}$.

1 A primeira separação por motivos militares, quando D. Luís defende o Tiu durante a Guerra dos Sete Anos e, mais tarde, quando D. Leonor vai a Lisboa resolver questões pendentes da Casa de Mateus e também quanto ao início da educação formal do filho mais velho. 
Uma das viagens que sua função exigia, que foi também a mais longa, foi a estadia na cidade de São Paulo. D. Luís foi escolhido como Governador da Capitania de São Paulo, onde deveria ficar durante três anos, como era o habitual. No entanto, o esposo de D. Leonor governou durante1o anos. $\mathrm{O}$ afastamento ainda foi mais longo, visto que a sede da Capitania, era de difícil acesso, levando a muitos meses de viagem. Durante este período, a esposa administrou sua Casa em Portugal e manteve seu marido à par dos acontecimentos na sua família; ou seja, cuidou da Casa de Mateus, uma atividade que não era regularmente feita por uma mulher, sendo que seus filho e filhas estavam em Lisboa, junto a sua avó materna.

O casal teve quatro filhos: José Maria do Carmo (1758-1825)², o mais velho e favorito de sua mãe, que, mais tarde, destacou-se na vida militar e diplomática, e também através de sua edição de Os Lusiadas; Maria do Carmo (1761-1820), que se casou com o Barão de Messâmedes em 1761; António, nascido 1762, e Francisca em 1763. Estes dois últimos morreram cedo, Francisca ainda criança, durante o período em que D. Luís esteve sob o Governo de São Paulo, e o menino com cerca de 18 anos.

Após os dez anos de governo no Brasil, unidos aos dois anos de viagens entre Portugal e a Capitania de São Paulo, D. Luís retornou a Lisboa. O reencontro entre o casal não foi pacífico e após morarem juntos por um curto período, se separam definitivamente. D. Luís morando em Mateus, onde veio a perecer em 1798, e D. Leonor em Lisboa, falecendo 8 anos após seu marido.

2 O filho mais velho casou-se duas vezes. A primeira com D. Maria Teresa de Noronha, a mãe de seu filho José Luís. Sua segunda esposa foi D. Adelaide Marie Emilie Filleuil de la Bellarderie, que era viúva do Conde de Flahâut e escreveu muitos romances. 
Em circunstância da recriação da Capitania de São Paulo, D. Luís foi escolhido como o novo Governador. Para morgado de Mateus, ele havia encontrado a capitania abandonada pela coroa. A distância da Capitania da Bahia e a dificuldade de acesso ao local de sua capital (o acesso era terrestre, e, após chegar aos portos, o trajeto era feito por meio de estradas entre as matas, o que denotava uma longa e cansativa viagem) fizeram com que São Paulo estivesse isolado do governo português. Assim, quando assumiu o cargo, morgado viu a necessidade de colonizar o vasto território e criar métodos de defendê-lo, fosse dos indígenas locais, fosse dos espanhóis em suas fronteiras. Durante seu governo, muitas picadas foram abertas, e tropeiros adentraram ainda mais a mata da região.

Em suas cartas, o governador menciona o desejo de ensinar aos indígenas técnicas portuguesas de plantio, por exemplo, mas não obteve sucesso na tentativa de diversificar a alimentação local. $\mathrm{O}$ governador tentara criar novas vilas e povoações, abrir e revitalizar caminhos, organizar o sistema militar da região e defender o sul da colônia. Para o morgado, o fato de que a capitania havia sido esquecida pelo governo português dificultava ainda mais seu trabalho; para ele, "ressuscitá-la é mais difícil do que criá-la de novo" (BELLOTO, 2007, p. 31).

Durante seu governo no Brasil, D. Luís não só mantinha contato com a esposa, que lhe escrevia constantemente, mas também com oficiais da Coroa. Embora as próprias cartas de D. Leonor indiquem que a comunicação entre eles era constante, foram poucas as cartas do morgado para sua esposa que sobreviveram ao tempo. O morgado tinha o costume de guardar todos os documentos, tendo orgulho de seu arquivo pessoal. Devido a isto, grande parte das cartas que recebeu de sua esposa durante sua estada no Brasil foram mantidas intactas e estão, atualmente, no Arquivo da Casa de Mateus, próximo a Vila Real, onde foram encontradas por Heloisa Bellotto e publicadas no livro Nem o tempo, nem a distância. Todas estas cartas tratam de 
temáticas da vida privada. Os assuntos do correio entre eles variavam entre questões da Casa de Mateus e o tratado e a saúde dos filhos.

No fim de sua estadia em São Paulo, o morgado de Mateus havia se desentendido com o Ouvidor da capitania, além de ter conflitos de interesses com a elite local. Além disto, o seu foco na Fortaleza do Iguatemi, no limite leste da região, mesmo após ter recebido ordens expressas para que focasse a defesa do Brasil mais ao sul, levou ao seu regresso para Portugal. Ainda assim, sua estadia como governador da capitania durou mais tempo do que era esperado, visto que os mandatos eram tipicamente de três anos.

O governador chegou a Lisboa em 17 de abril de 1776. Sua esposa o esperava no porto, no entanto, ambos desaprovavam um ao outro. Não ter seguido os desejos da Coroa Portuguesa (ou, na altura, de marquês de Pombal) fez com que o morgado não conseguisse o almejado título de conde quando retornou a Portugal. Mas sua esposa havia mantido amizades políticas importantes (nomeadamente, a do próprio marquês de Pombal) enquanto ele estivera no Brasil, e, por intermédio disto, o morgado tentou aproveitar-se desta relação para conseguir o título que mais tarde será dado a seu neto.

Ainda que o morgado e sua esposa tenham constantemente declarado o desejo de se reencontrarem em suas cartas, quando isto acontece o casal logo se desentende. A situação entre os dois se agravou de tal maneira, que após uma agressão física, eles se separaram, o que os levou a confrontos jurídicos por parte de ambos (BELLOTO, 2007, p. 38), sendo que a participação feminina nestes - e não através de familiares homens que a representassem - era incomum no período. D. Leonor fez, inclusive, reclamações à rainha, D. Maria I. Como já referido, passaram a morar em diferentes cidades, a esposa próxima ao círculo social em que havia sido criada em Lisboa, e o marido em seu morgadio de Mateus, onde posteriormente recebeu e educou seu neto José Luís, até ter falecido em 1798. 


\section{O cotidiano familiar e os filhos}

As cartas apresentam o cotidiano da família e dos habitantes da Casa de Mateus. Desta forma, temáticas como a educação e a saúde dos filhos são frequentes. Para Michelle Perrot, a maternidade era um importante tema para a vida das mulheres (PERROT, $2008 \mathrm{p}$. 88), o que se demonstra na presença dos filhos nestes textos. Não obstante, tais escritos também seriam, de certa forma, documentos que serviriam para informar o marido de acontecimentos políticos e públicos. São, então, uma mistura entre público e privado, fonte de informações sociais e pessoais. A maior parte missivas menciona o filho mais velho do casal, e, quando já estavam separados, o neto.

Durante o afastamento do marido da Casa de Mateus durante sua carreira militar na defesa de Tua, período no qual sua esposa estava grávida, suas cartas mencionam temáticas diretamente relacionadas à maternidade e à feminilidade. $\mathrm{O}$ fato de que a esposa esperava uma criança é grande parte da justificativa de uma temática tão pessoal figurada nas cartas. Textos de outras senhoras, mesmo quando enviadas a outras mulheres, pouco mencionava questões tão pessoais relacionadas ao corpo feminino.

No período em que viveu D. Leonor, o uso de amas de leite era parte do cotidiano familiar das mulheres da elite portuguesa, o que continuou durante grande parte do século seguinte. Em Portugal, as amas acompanhavam as famílias (como acontece no caso da família do morgado de Mateus, ou na família de outra fidalga portuguesa que teve suas cartas publicadas postumamente, a condessa de Alva (ALVA, 2006) ${ }^{3}$; por outro lado, na França descrita por Edward Shorter, os bebês eram deixados em casas pobres nas proximidades da capital, pois pensavam que o ar das fazendas faria melhor à criança

3 Sobre a maternidade nas missivas da Condessa de Alva, vide BIGUELINI , 2017, capítulo 4 , tópico 5 . 
que o ar (já então poluído) de Paris (SHORTER, 1995, p. 191), sob a guarda de mulheres que tinham mais de uma criança em seus cuidados, muitas vezes negligenciando-as. Neste mesmo período, a obra de Jean Jacques Rousseau já era conhecida entre as elites sociais, assim, já havia influenciado algumas mães da aristocracia a amamentarem seus recém-nascidos. No entanto, esta prática não era ainda corrente no Portugal setecentista. Já na segunda metade do século XIX, no entanto, algumas mulheres passaram a utilizar esta prática, tal como a memorialista Josefina de Neuville, que não discutiu o assunto, mas não teria como pagar uma ama para cuidar de suas filhas (NEUVILLE, 1864) ${ }^{4}$.

O final do século XVIII e o início do XIX marcaram a forma como a sociedade percebia o aleitamento materno, visto que foi um momento de mudança no pensamento relacionado à privacidade e à intimidade. É devido a essa mudança de paradigma que autores como Phillipe Ariés demarcam este momento como o surgimento da criança (ARIÈS, 1981), ou seja, é a partir de então que estas passam a ser percebidas não apenas como pequenos adultos, mas sim como indivíduos que precisam ser cultivados. Edward Shorter descreve uma certa "desatenção maternal" até este momento, no qual a figura da criança começa a se tornar importante para a família (SHORTER, 1995, p. 186). A hipótese de que não haveria sentimento materno é corroborada por esta negligência, no entanto, o que percebemos nas cartas de D. Leonor a seu marido é que não há descaso para com os filhos. Se a mortalidade infantil era grande, isto não parece impedir os pais de sentirem a perda filial.

Como membro da aristocracia portuguesa do Setecentos, D. Leonor não poderia ser vista amamentando. Não seria bem aceita pela

4 Sobre a maternidade na obra de Neuville, vide BIGUELINI, 2017, capítulo 4, tópico 5 e BIGUELINI, 2018. 
sociedade, ou considerada digno de uma fidalga. A escolha da ama tem, então, uma relevância muito grande para a continuidade do sucesso da Casa de Mateus. Logo, o casal não se cansaria até encontrar o que seria a ama de leite ideal. Em carta datada de janeiro de $175^{8}$ por Heloisa Belloto, D. Leonor comenta sobre o assunto: "Esqueci-me de dizer-lhe que, se totalmente quer a ama, que a mande a tempo de descansar do caminho por amor do leite, e avise-me para despedir-me as outras de Rechião.” (BELLOTO, 2007, Carta 5, p. 63) Percebe-se, assim, o cuidado na escolha da ama. Muitas mulheres já haviam sido consultadas para o cargo.

Percebe-se também aqui uma atenção masculina relacionada aos filhos. Também o morgado se preocupa com a escolha. Ou seja, não cabe exclusivamente à mulher, ainda que a elas fosse destinado tudo que era referente ao privado, segundo padrões sociais. Na carta seguinte o assunto é retomado:

No que toca à ama muito me custa afastar-me do seu gosto, $\mathrm{e}$ também porque tenho a mesma sua esperança de que quase sempre quanto mais se escolho menos se acerta, e bem sabe sempre gostei da monja e conheço as suas boas circunstâncias, mas ontem perguntado-me se tinha ama e dizendo-lhe que muito boa só tinha algum jeito em uma, que me pediu Dona Clara que pelo amor de D. Luís tal não fizesse, que tem uma filha torta filha da ama e outra em casa com o mesmo e assim não é justo que se Deus não fizer o grande favor de nascer sem defeito por nossa culpa o tenha, de Rechião vieram duas à mostra, uma aprovou o Cabral e o Lourenço mas se não quiser determina o que lhe parecer (BELLOTO, 2007, Carta 6, p. 65).

Dona Leonor promete seguir a designação de D. Luís, levando em consideração a opinião do marido em um assunto que é visto, então, como essencialmente feminino. Mas suas cartas também revelam um medo frequente em seu período: uma filha torta filha da ama. Para a esposa do morgado é possível que características da mãe se- 
jam passadas para o bebê através do leite. Assim, ela deseja escolher uma ama que não iria 'passar seus defeitos físicos' para a filha que esperava. Segundo Badinter (1986), algo semelhante à mamadeira para o leite de vaca só passa a ser usada no século XVIII, visto que "segundo um preconceito solidamente enraizado na mentalidade popular, pensa-se que se mama com o leite também o caráter." (BADINTER, 1986, p. 120). Este medo é tanto fruto de um racismo intrínseco à sociedade portuguesa do século XVIII, como também provém do desconhecimento do período sobre a verdadeira fisiologia do leite.

Assim, o medo de D. Leonor de que o leite de uma ama imperfeita cause imperfeição ao bebê nasce de uma opinião preconceituosa do leite materno. Este medo também aparece em outra carta desta senhora, na qual explicou ao marido que "a monja era boa, mas como tem um jeito em um olho não serve que é muito perigoso para crianças que fazem o mesmo que vêem" (BELLOTO, 2007, Carta 9, pp. 69-70). Este temor os levou a discutirem intensamente a questão, como estas cartas permitem perceber.

A escolha da ama apresenta um momento importante para o casal, visto que além de demonstrar o interesse na segurança do filho, $\mathrm{e}$ também que o bem-estar das crianças é um desejo de ambos os pais. Mostra que, apesar do trato com os filhos ser uma atividade feminina, o pai poderia também interferir nas decisões do assunto; ainda mais quando estas decisões teriam impacto sobre sua própria vida. Ao amamentar a criança, a mãe ficava impossibilitada (segundo os padrões sociais da época) de frequentar a cama do marido. Não amamentar era, então, uma escolha dos casais da elite portuguesa pela continuidade do contato íntimo entre marido e mulher.

Não lhe importava apenas escolher uma ama digna de confiança, mas também fisicamente parecida a ela, sendo que escreve ao marido que "não se esqueça da ama que não tenha nada nem de judia nem de mulata que é muito preciso estas circunstâncias” (BELLOTO, 
2007, Carta 7, p. 67). Também demonstra preconceitos contra mulheres negras ou judias, comuns em um Portugal católico e branco.

Após todos estes detalhes na escolha da ama, o medo de que esta possa causar mal à criança também aparece nas missivas de D. Leonor, que conta ao marido o caso do filho de Margarida Isabel: "já se sabe toda a verdade, que a ama o matou avultando-se sobre ele com o sono e não só o sufocou como aleijou de uma mãe e pena forte desgraça, sem batismo" (BELLOTO, 2007, Carta 13, p. 77).

Este medo não parece ser infundado, visto que aquelas que precisavam se tornar amas deixavam seus filhos com terceiros, e tinham que continuar produzindo leite por muitos anos. O medo de informar a sua senhora de que o leite acabou levou ao falecimento de um dos filhos da condessa de Alva, por exemplo, que descobre apenas depois que a criança faleceu porque sua ama já não produzia o alimento há vários dias (ALVA, 2006, p. 259).

A procura pela ama era feita tanto pelo marido quanto pela esposa, mas após longo tempo, a senhora dizia ao marido que "se a não achar não se consuma que eu procurarei" (BELLOTO, 2007, Carta 9, p. 70), ainda que D. Luís lhe escrevera de Baião que "aqui já temos umas poucas de amas. parece-me que agora não haverá tanta dificuldade em se acharem como nos quisermos nestes concelhos" (BELLOTO, 2007, Carta 57, p. 179). Por fim, menções futuras à monja indicam que esta tenha sido a escolhida. Ainda que o marido discutisse o assunto, a escolha final era feita pela mãe da criança, visto que era ela que iria conviver com a ama.

A crença de que defeitos tanto físicos quanto morais seriam recebidos pela criança era compartilhada pelo morgado de Mateus. Mas este também demonstrava conhecer os benefícios do aleitamento materno e de uma criança próxima à mãe, quando afirma que Maria do Carmo aprendeu e se interessou pela língua inglesa devido ao interesse da mãe: 
As meninas estão lindas, a mais velha tem melhorado muito desde que se lhe deu leite de peito, esta era a sua falta: já não está muito magra como era, fala muito mas tudo inglês, explica-se com nomes novos todos figurados em 'The', cuido que foi Dona Leonor andar aprendendo aquela língua (BELLOTO, 2007, Carta 59, p. 183).

Posteriormente, após o nascimento da segunda filha e a viagem da mãe a Lisboa, o pai ficou a cargo de cuidar do novo membro da família. Logo, quando a ama de sua filha pediu para visitar sua própria filha, ele fez de tudo para que esta ficasse em Mateus e cuidasse da menina Francisca:

A mais nova está muito bem criada, mas tem-me custado muito acomodar a ama e conservá-la porque lhe adoeceu a filha; esteve muito tempo doente e enfim morreu-lhe um destes dias; para a acomodar com tudo isto considere o que me terá custado. (BELLOTO, 2007, Carta 32, p. 118).

Neste último trecho, percebe-se que a filha da ama não é vista com importância pela família. Segundo Shorter (1995) e Badinter (1986), isto é recorrente. Amas renegam seus próprios filhos para cuidar de filhos alheios, sejam estes da nobreza ou não. E como estas figuras, assim como seriam preceptoras ou outras serventes do lar, ainda que membros da Casa e como tal tivessem um papel importante na vida do morgado e de sua família, não têm a mesma relevância que figuras que carregam consigo o nome de Mateus. Mas ainda que a ama-de-leite tivesse valor para a família, sua criança não o tem.

Pouco se sabe sobre as amas-de-leite em Portugal, lembra Isabel dos Guimarães Sá (SÁ, 2011, p. 78). As missivas do casal de Mateus, então, tornaram-se uma fonte interessante para conhecer a real necessidade desta figura dentro do lar setecentista português. Como a família de Mateus era membro da elite portuguesa, a ama escolhida 
passava a habitar o ambiente familiar. Ela cuidaria da criança, além de amamentá-la, ao contrário das famílias da burguesia, em França, onde as crianças eram levadas à casa de uma ama, e por vezes nesta restavam durante anos depois de desmamadas (BADINTER, 1986, p. 123), o que levava a uma grande morbilidade infantil, devido aos maus cuidados e a sujidade (SHORTER, 1995, pp. 194-195). Nota-se, no entanto, que esta diferença não significava que as crianças não faleciam no cenário português.

Não era apenas quando a distância entre o casal era pequena que D. Leonor se dirigia ao marido se dirigia ao marido na escolha da pessoa que cuidaria dos bebês da família ou quanto à educação de seus filhos. Lembramos que durante a estada deste no Brasil, D. Leonor não tinha outra opção senão seguir com a gerência da casa sem o auxílio masculino. Mas, quando a distância entre eles era inferior a um oceano, ela pedia a opinião de seu marido em diversas situações.

D. Leonor, grávida, foi a Lisboa para resolver questões referentes à Casa de Mateus e à educação de José. D. Luís, por sua vez, demonstrou nas cartas que esteve muito presente durante os anos em que suas filhas e seu filho mais novo eram pequenos. Não apenas os mencionou constantemente, como zelou pessoalmente pela saúde da filha quando esta esteve doente:

(Q)uinze dias a sustentei com a minha habilidade, fazendo-lhe passar alguma coisa líquida com grandíssimo trabalho por meio de alguns instrumentos e jeitos que se lhe procuravam, sem ela querer estar quieta pelas muitas dores que padeciam (BELLOTO, 2007, Carta 32, p. 117).

Este trecho, no qual também se percebe que o morgado tinha interesse por assuntos da medicina, nota-se a relação próxima entre pai e filhos, o que não era comum no então cenário. A saúde das crianças, assim como a saúde do próprio casal, é uma temática presente na maioria das cartas. 
A proximidade do D. Luís e de seus filhos, assim como o carinho que ele apresenta pelo neto, é perceptível também quando ele afirma que "filhos longe de seus pais também tem seus inconvenientes" (BELLOTO, 2007, Carta 65, p. 194).

Para além do propósito de informar o marido sobre os filhos as missivas tinham uma função de relatar os acontecimentos mais importantes para a Casa. E nada seria mais marcante do que o falecimento de uma das filhas, conforme D. Leonor escreveu:

(A)doeceu Francisca e morreu, além de filha, a mais linda e discreta e habilidosa menina que eu vi cuja saudade me não pode passar desejando se trocasse em agradecimentos a meu Senhor da fortuna que logre para que não posso mais continuar sem lágrimas (BELLOTO, 2007, Carta 129, p. 340).

Assim, não comenta nem como a menina morreu, nem escreve mais sobre o assunto. É uma carta informativa que, à primeira vista, demonstra falta de sentimento para com a jovem criança. A morte da menina só é mencionada nas cartas uma segunda vez, quando D. Leonor, doente, se recusa a ser vista por médicos de Lisboa: “Como Francisca tinha ido para o céu não quis chamar nenhum médico de Lisboa" (BELLOTO, 2007, Carta 131, p. 343).

Aqui sim está claramente presente o sentimento maternal. Perdeu a filha na mão de médicos de Lisboa e, logo, carrega consigo um rancor para com estas pessoas que não conseguiram salvá-la.

É possível que haja cartas perdidas entre esta e as seguintes que mencionem com maior sentimento a perda da filha, no entanto, estas epistolas não têm o objetivo de serem uma conversa entre duas pessoas que se amam e, sim, entre dois líderes de um grupo familiar. Servem apenas como informe e não como desabafo sentimental.

É importante lembrar, no entanto, que a mortalidade infantil era parte comum da vida de um casal durante o século XVIII. Isabel 
dos Guimarães Sá afirma que "jamais os primogenitores das crianças pensariam que todos os seus filhos chegariam à idade adulta" (SÁ, 2011, p. 73). Mas isto não impedia que o sentimento de perda fosse grande.

Nas cartas seguintes à morte da filha, D. Leonor se preocupa com uma sobrinha que recusa o casamento. Este assunto a leva a mencionar o choro constantemente, mas a morte da filha não parece causar o mesmo efeito. No entanto, como a primeira carta refere-se à impossibilidade de escrever sobre o assunto sem chorar, pode ser esta a razão de não ser novamente mencionada a perda da criança. Sobre a morte de crianças, D. Leonor havia exposto sua opinião quando seu marido participava da defesa de Tua, afirmando que "a dor de ver padecer um filho não se conhece senão a experimentação" (BELLOTO, 2007, Carta 12, p. 78). Não sobreviveram cartas do morgado sobre o assunto.

Por sua vez, a morte do filho mais novo, António, em 1780, não aparece nas cartas aqui analisadas, visto que ele morreu após o pai ter voltado para Portugal, mas antes do reinício das cartas disponíveis.

Segundo Badinter, o falecimento dos filhos era pouco registrado (BADINTER, 1986, p. 84), visto que muitas crianças morriam ainda na primeira infância, em parte devido ao "descuido" a que se refere Shorter e mencionado anteriormente. Isso não significa que a morte destas crianças não era sentida pelos familiares, mas sim que se tornara um acontecimento comum.

Outra figura infantil de relevância nas cartas entre o morgado de Mateus e sua esposa é o neto José. Educado por sua avó (assim como os filhos haviam sido educados pela mãe de D. Leonor), o menino morava em Lisboa e visitara o avô uma única vez, meses antes de sua morte. D. Luís se demonstrava constantemente preocupado com a saúde a educação do neto e pedia que sua esposa o enviasse para o Solar de Mateus. 
Durante a visita do menino, fez questão de mostrar-lhe a Capela à Nossa Senhora dos Prazeres e o aconselhou a não aprender matemática, visto que seria herdeiro do morgadio de seu avô e esta ciência não lhe seria necessária, mas que aprendesse no lugar tudo que lhe fosse útil para o morgadio.

\section{Conclusão}

O que se percebe nas cartas entre D. Leonor e seu marido é um constante interesse pelo bem-estar dos filhos, seja na discussão sobre a ama-de-leite, seja sobre a educação dos filhos e do neto. Pode-se perceber o interesse tanto feminino quanto masculino pela formação das crianças, fosse esta física (por meio da escolha da ama-de-leite) ou mental.

O sentimento maternal está presente em todas as missivas, ainda que elas sejam mais uma descrição de acontecimentos do que textos expressivos de sentimentos guardados e revelados apenas para o marido. Surpreendente é, no entanto, a forma como o marido também se preocupa com estes afazeres supostamente (ou socialmente concebido como) femininos. O governo da Casa de Mateus era misto em ambos os lados. Ao mesmo tempo em que a figura do marido aparece frequentemente relacionada ao tratado com os filhos, também a esposa participa ativamente das atividades político- socias do casal. É por meio das amizades dela que a família finalmente recebe o condado, e é através dele que se faz a procura pela ama. Este modelo de gestão familiar não era comum durante o século XIX, mas demonstra que as mulheres, ainda que relegadas a espaços sociais limitados, tinham um poder verdadeiro dentro da sociedade. Comandavam sua casa, mas também a Casa da família e de seus agregados.

Por meio das cartas entre o morgado e sua esposa podem ser descobertos momentos familiares reais e percebido, acima de tudo, a 
importância da Casa. Não do lar, mas sim dos membros da família e da importância de manter o nome do morgadio; seja através da boa educação, seja através da boa formação dos filhos do casal. Demonstram que, ao menos para este casal, o fato de que muitas crianças faleciam ainda pequenas não interfere no sentimento que os familiares têm por elas. A dor da perda não cessa somente porque a mortalidade infantil era alta.

As missivas trocadas entre um vasto oceano permitem que historiadores percebam nuances de uma vida particular que é, normalmente, escondida dos olhares da História, devido a sua privacidade, por mais público que fosse o ato da escrita.

RECEBIDO: 23/11/2020 APROVADO: 21/06/2021

\section{REFERÊNCIAS}

ALVA, Condessa de. Mariana de Sousa Holstein. In: VENTURA, António (Org.). Um olhar feminino sobre Portugal. D. Mariana de Sousa Holstein. Condessa de Alva. Cartas a sua irmã Teresa (1814-1819). Lisboa: Livro Horizonte, 2006.

ARIÈS, Philippe. História Social da Infância e da Família. $2^{\mathrm{a}}$ ed. Rio de Janeiro: LTC, 1981.

BADINTER, Elizabeth. $O$ amor incerto: História do Amor maternal do século XVII ao XX. Lisboa: Relógio D’água, 1986.

BELLOTO,Heloisa Liberalli.Nemotempo,nemadistância:correspondência entre o Morgado de Mateus e sua mulher, D. Leonor de Portugal (175798). Lisboa: Aletheia editores, 2007.

BIGUELINI, Elen. "Tenho escrevinhado muito": mulheres que escreveram em Portugal (1800-1850). 2017. 507 f. Tese (Doutorado em Altos Estudos em História) - Universidade de Coimbra, Coimbra, 2017.

. Minhas Queridas Filhas, Esses Dois Thesouros De Minh'alma':

O Amor Materno Em Josephine De Neuville (1823-1889). In. Anais X Seminário de Pesquisa II Encontro Internacional VII Jornada Intermídia. Curitiba: Uniandrade, 2018. pp. 162-17o.

BOLOGNE, Jean-Claude. Histoire du Mariage en Occident. Mesnil-surl’Estrée: Jean-Claude Lattès, 1995. 
CASEY, James. A História da Família. São Paulo: Editora Ática, 1992.

CUNHA, Mafalda Soares da; MONTEIRO, Nuno Gonçalo. As grandes casas. In: MATTOSO, José (Dir.). História da Vida Privada de Portugal. A Idade Moderna. Lisboa: Círculo de Leitores e Temas e Debates, 2011. pp. 202-243.

FLEXOR, Maria Helena Ochi. As vilas pombalinas do século XVIII: estratégias de povoamento. Anais do Museu Paulista. V Seminário de História da Cidade e do Urbanismo da Pontifica Universidade Católica de Campinas,. São Paulo: Puccamp,1998.

. Núcleos urbanos planejados do século XVIII. Revista de Urbanismo e Arquitetura, 1, Salvador, 1988, pp. 89-114. Disponível em < http://repositorio. ufba.br/ri/handle/ri/31167 >. Acesso em: 06 de julho de 2021.

GILBERT, Sandra M; GUBAR, Susan. The Madwoman in the attic: The Woman Writer and the nineteenth-Century Literary Imagination. New Haven and London: Yale University Press, 1984.

LOPES, Maria Antónia. Mulher, Espaço e Sociabilidade: A transformação dos papéis femininos em Portugal à luz de fontes literárias (segunda metade do século XVIII). Lisboa: Livros Horizonte, 1989.

MUNHOZ, Renata Ferreira. Correspondência oficial para o Morgado de Mateus: Transcrição semidiplomática do livro no 170 do AESP (de 1767 a 1775). 554 f. Dissertação (Mestrado em Filologia e Língua Portuguesa) - Faculdade de Filosofia da Universidade de São Paulo, São Paulo, 2009. Disponível em: < http://www.teses.usp.br/teses/disponiveis/8/8142/tde01122009-152250/ >. Acesso em: 19 de jun. de 2013.

NEUVILLE, Josefina de. Memórias da minhavida: recordações das minhas viagens por Josephina Neuville dedicadas a minhas filhas offerecidas a *** 2 volumes. Lisboa: Typographia do Panorama, 1864.

PERROT, Michelle. 'Mi' historia de las mujeres. Trad.: Mariana Saúl. Buenos Aires: Fondo de Cultura Económica, 2008 (2006).

ROUSSEAU, Jean-Jacques. Émile, ou, De l'éducation: introdução e anotações de Henry Legrand. Paris: Larousse, 1914 (1762).

La Nouvelle Héloïse. Paris: Libraries des Firmin Didot Frères, 1846. (1761).

SÁ, Isabel dos Guimarães. As crianças e as idades da vida. In. MATTOSO, José (Dir.). História da Vida Privada de Portugal. A Idade Moderna. Lisboa: Círculo de Leitores e Temas e Debates, 2011. pp. 72-95. 
SHORTER, Edward. A formação da família moderna. Lisboa: Terramar, 1995. TORRÃO FILHO, Almicar. O sumo bem contra a ruína da sociedade: o Morgado de Mateus, a Fundação do Recolhimento da Luz e a Mística Feminina em São Paulo. São Paulo: Museu de Arte Sacra de São Paulo. Disponível em: < http://www.museuartesacra. org.br/artigo_amilcar.pdf $>$. Acesso em: 19 de jun. de 2013.

\section{MinicurRículo}

Elen Biguelini é doutora em Altos Estudos em História pela Universidade de Coimbra, Mestra em Estudos Feministas pela Universidade de Coimbra, Bacharel e Licenciada em História pela UFPR. Tem a pesquisa focada em temáticas relacionadas a feminilidade e a autoria feminina, em especial de autoria portuguesa durante o século XIX, e em Jane Austen e Elizabeth Inchbald (inglesas). 